\title{
Sodium-Taste Cells Require Skn-1a for Generation and Share Molecular Features with Sweet, Umami, and Bitter Taste Cells
}

\author{
Makoto Ohmoto, ${ }^{1,2, *}$ Masafumi Jyotaki, ${ }^{1, *}$ J. Kevin Foskett, ${ }^{3,4}$ and Ichiro Matsumoto ${ }^{1}$
}

https://doi.org/10.1523/ENEURO.0385-20.2020

${ }^{1}$ Monell Chemical Senses Center, Philadelphia, PA $19104,{ }^{2}$ Center for Biological Resources and Informatics, Tokyo
Institute of Technology, Yokohama 226-8501, Japan, ${ }^{3}$ Department of Physiology, University of Pennsylvania,
Philadelphia, PA 19104, and ${ }^{4}$ Department of Cell and Developmental Biology, Perelman School of Medicine,
University of Pennsylvania, Philadelphia, PA 19104

\begin{abstract}
Taste buds are maintained via continuous turnover of taste bud cells derived from local epithelial stem cells. A transcription factor Skn-1a (also known as Pou2f3) is required for the generation of sweet, umami (savory), and bitter taste cells that commonly express TRPM5 and CALHM ion channels. Here, we demonstrate that sodium-taste cells distributed only in the anterior oral epithelia and involved in evoking salty taste also require Skn-1a for their generation. We discovered taste cells in fungiform papillae and soft palate that show similar but not identical molecular feature with sweet, umami, and bitter taste-mediated Type II cells. This novel cell population expresses Plcb2, Itpr3, Calhm3, Skn-1a, and ENaC $\alpha$ (also known as Scnn1a) encoding the putative amiloride-sensitive (AS) salty taste receptor but lacks Trpm5 and Gnat3. Skn-1a-deficient taste buds are predominantly composed of putative non-sensory Type I cells and sour-sensing Type III cells, whereas wild-type taste buds include Type II (i.e., sweet, umami, and bitter taste) cells and sodium-taste cells. Both Skn-1a and Calhm3-deficient mice have markedly decreased chorda tympani nerve responses to sodium chloride, and those decreased responses are attributed to the loss of the AS salty taste response. Thus, AS salty taste is mediated by $S k n-1 a-d e p e n d e n t$ taste cells, whereas amiloride-insensitive salty taste is mediated largely by Type III sour taste cells and partly by bitter taste cells. Our results demonstrate that Skn-1a regulates differentiation toward all types of taste cells except sour taste cells.
\end{abstract}

Key words: salty; Skn-1a; sodium taste; taste cell

\section{Significance Statement}

Salty taste plays an important role in electrolyte homeostasis in body fluids. Other basic tastes are each mediated by specialized sensory cells and elicits either preference or avoidance; in contrast, salty taste elicits both behaviors, depending on concentrations, and is mediated by multiple mechanisms and cell types that are poorly defined. We report that a subset of cells that express $\mathrm{ENaC} \alpha$ exhibit a gene expression profile similar but not identical to sweet, umami, and bitter taste cells. They mediate amiloride-sensitive (AS) sodium taste and rely on Skn-1a for their generation and the CALHM ion channel for neurotransmitter release. Amiloride-insensitive (Al) salty taste is partially mediated by sour taste cells, the only taste cells present in the Skn-1a knock-out mice.

Received September 5, 2020; accepted November 10, 2020; First published November 20, 2020.

The authors declare no competing financial interests.
Author contributions: I.M. designed research; M.O. and M.J. performed research; J.K.F. contributed unpublished reagents/analytic tools; M.O., M.J., and I.M. analyzed data; M.O., J.K.F., and I.M. wrote the paper. 


\section{Introduction}

Individual taste cells mediate one of five basic tastes in mice: sweet, umami (savory), bitter, sour, and salty by sodium salts (Yarmolinsky et al., 2009; Chandrashekar et al., 2010; Matsumoto et al., 2013). Whereas they express their own taste receptors, sweet, umami, and bitter taste cells share an intracellular signal transduction mechanism comprising phospholipase $\mathrm{C} \beta 2$ (PLC $\beta 2$ ), inositol triphosphate receptor type $3\left(\mathrm{IP}_{3} \mathrm{R} 3\right), \mathrm{Ca}^{2+}$-dependent monovalent cation channel TRPM5, and voltage-dependent ATP release channel CALHM1/3 (heterooligomeric channel composed of CALHM1 and CALHM3; Liu and Liman, 2003; Zhang et al., 2003; Hisatsune et al., 2007; Taruno et al., 2013; Ma et al., 2018). Sour taste cells have a different molecular signature, specifically expressing Pkd2/1, Otop1, and Car4 but not Plcb2 or Trpm5 (Huang et al., 2006; Chandrashekar et al., 2009; Chaudhari and Roper, 2010; Tu et al., 2018). In contrast, the specific molecular features of the cells that mediate taste evoked by sodium are poorly defined.

Sodium chloride $(\mathrm{NaCl})$ evokes salty taste via amiloridesensitive (AS) and amiloride-insensitive (Al) mechanisms in taste cells. The AS mechanisms are specific for $\mathrm{NaCl}$ and are involved in the attractive responses to $\mathrm{NaCl}$ (Chandrashekar et al., 2010; Tordoff et al., 2014; Nomura et al., 2020). In contrast, the Al mechanisms respond to many salts and mediate aversive responses (Oka et al., 2013). The taste cells that mediate AS and Al salt-sensing mechanisms represent distinct populations (Yoshida et al., 2009; Chandrashekar et al., 2010; Roebber et al., 2019). The AS NaCl-sensing taste cells responsible for sodium preference (hereafter referred to as sodium-taste cells) reside in taste buds of fungiform papillae (FuP), but not in circumvallate papillae (CvP), and express the epithelial sodium channel ENaC as the sodium sensor and CALHM1/3 (Chandrashekar et al., 2010; Tordoff et al., 2014; Nomura et al., 2020). In the CvP all taste cells that co-express Calhm1, Calhm3, and Trpm5 depend on Skn1a for their generation (Taruno et al., 2013; Ma et al., 2018). Furthermore, Skn-1a-deficient mice showed a partial loss of sodium taste responses of gustatory nerves (Larson et al., 2020). Nevertheless, it has been suggested that sodium-taste cells are distinct from Trpm5-expressing $\left(\right.$ Trpm $^{+}$) cells and sour taste cells (Chandrashekar et al., 2010). Thus, whereas the specific cell type involved in attractive responses to $\mathrm{NaCl}$ share some features with sweet, umami, and bitter taste cells, it appears to be distinct from them. The identity of specific cell types responsible for the aversive Al salt-sensing mechanisms is also

This work was supported by National Institutes of Health Grants R01DC015491 and R01DC017503 (to I.M.) and R01DC012538 (to J.K.F.). M.O. is supported by the Lotte Shigemitsu Prize.

${ }^{*}$ M.O. and M.J. contributed equally to this work.

Correspondence should be addressed to Ichiro Matsumoto at imatsumoto@ monell.org.

https://doi.org/10.1523/ENEURO.0385-20.2020

Copyright (C) 2020 Ohmoto et al.

This is an open-access article distributed under the terms of the Creative Commons Attribution 4.0 International license, which permits unrestricted use, distribution and reproduction in any medium provided that the original work is properly attributed. uncertain. It has been reported that taste cells that respond to all $\mathrm{Cl}^{-}$-containing solutions, including $\mathrm{HCl}$, are $\mathrm{Al}$ and lack ENaC $\alpha$ expression (Yoshida et al., 2009). Alternately, it has been suggested that Al salt-taste mechanisms reside in bitter taste cells and sour taste cells that express ENaC $\alpha$ (Chandrashekar et al., 2010; Oka et al., 2013). In contrast, it was recently proposed that $\mathrm{Al} \mathrm{NaCl}$ taste resides in sweet and bitter taste cells but not in sour taste cells (Roebber et al., 2019).

Taste cells are epithelial sensory cells that are maintained in taste buds by continuous turnover (Beidler and Smallman, 1965). They are derived from local epithelial stem cells that express Sox2 and Krt5 commonly (Stone et al., 1995; Ohmoto et al., 2017, 2020). At the precursor cell stage of taste cell differentiation, a POU homeodomain transcription factor Skn-1a (also known as Pou2f3) specifies the fate of a cell as a sweet, umami, and bitter cell lineage (Matsumoto et al., 2011). Interestingly, Skn-1a is also required for differentiation of putative sensory cells in other tissues including microvillus cells in the main olfactory epithelium, solitary chemosensory cells in the respiratory epithelium, and tuft cells in the intestine, all of which commonly express Trpm5 similar to sweet, umami, and bitter taste cells (Ohmoto et al., 2013; Yamaguchi et al., 2014; Gerbe et al., 2016). Skn-1a therefore appears to be a master regulator of Trpm5-expressing sensory cells (Yamashita et al., 2017).

In the present study, we found that taste cells responsible for AS avidity to $\mathrm{NaCl}$ share some molecular features with sweet, umami, and bitter taste cells but are distinct from them. AS responses of the chorda tympani nerve to $\mathrm{NaCl}$ are abolished in both Skn-1a-deficient and Calhm3deficient mice that also lack perception of sweet, umami, and bitter tastes. The loss of AS neural responses in Skn1a-deficient mice was correlated with the disappearance of taste cells defined by a Calhm $3^{+} \operatorname{Trpm} 5^{-}$molecular identity. Thus, Skn-1a governs the generation of sodiumtaste cells in addition to sweet, umami, and bitter taste cells.

\section{Materials and Methods}

\section{Animals}

C57BL/6J (stock \#000664) mice were purchased from The Jackson Laboratory. Heterozygous $S k n-1 a^{+/-}$mice in a 129/B6 mixed background (Matsumoto et al., 2011) were crossed with C57BL/6J mice over 10 generations, and resultant male and female $S k n-1 a^{+/-}$mice with a C57BL/6J congenic background were crossed to obtain Skn-1a ${ }^{-/-}$mice with a C57BL/6J congenic background, which were maintained by crossing homozygous mice. Calhm3 ${ }^{-/-}$mice have a C57BL/6J background as described previously (Ma et al., 2018). Both sexes were used in all animal experiments, which were conducted according to a protocol approved by the Institutional Animal Care and Use Committee.

\section{Tissue preparation}

For fresh-frozen tissue samples, mice were deeply anesthetized with urethane, and the oral epithelia were 
Table 1: Probes used for in situ hybridization analyses

\begin{tabular}{lll}
\hline Gene name & Accession no. & Probe region \\
\hline ENaC $\alpha$ & BC133688 & $913-2333$ \\
Trpm5 & AF228681 & $310-3491$ \\
Calhm1 & LC270870 & $1-1407,2148-2369$ \\
Calhm3 & LC270871 & $1-1653$ \\
Itpr3 & BC023776 & $1-3447$ \\
Plcb2 & BC145249 & $588-3123$ \\
Gnat3 & AK040065 & $41-1019$ \\
Skn-1a & NM_011139 & $72-2363$ \\
Entpd2 & NM_009849 & $20-1822$ \\
Pkd2I1 & NM_181422 & $226-3275$ \\
\hline
\end{tabular}

dissected and embedded in O.C.T. compound (Sakura Finetech). For tissues fixed with $4 \%$ paraformaldehyde (PFA), mice were deeply anesthetized with urethane and transcardially perfused with PBS followed by $4 \%$ PFA in PBS. Dissected oral epithelia were postfixed, cryoprotected, and frozen as previously described (Ohmoto et al., 2008). Cryosections (8- $\mu \mathrm{m}$ thickness) were prepared using a Leica CM1900 cryostat (Leica Microsystems), mounted on tissue adhesive-coated glass slides (Fisher Scientific), and preserved at $-80^{\circ} \mathrm{C}$ until use.

\section{In situ hybridization}

In situ hybridization using fresh-frozen sections was conducted as previously described (Ohmoto et al., 2008; Taruno et al., 2013). Digoxigenin-labeled and fluorescein-labeled antisense RNAs were synthesized and used as probes after fragmentation to $\sim 150$ bases under alkaline conditions. The probe regions are shown in Table 1. Sections were fixed with 4\% PFA, treated with diethylpyrocarbonate, prehybridized with salmon testis DNA, and hybridized with the riboprobes for $40 \mathrm{~h}$. After hybridization, the sections were washed in $0.2 \times$ SSC. Prehybridization, hybridization, and washing were performed at $58^{\circ} \mathrm{C}$ except when using the riboprobes for Calhm 1, Itpr3, and $E N a C \alpha$, which were performed at $65^{\circ} \mathrm{C}$. After washing, chromogenic and/or fluorescence signals were developed as follows:

For single-label in situ hybridization, hybridized probes were detected using alkaline phosphatase-conjugated antidigoxigenin antibodies (Roche Diagnostics, 11093274910, RRID:AB_514497), and chromogenic signals were developed using 4-nitro blue tetrazolium chloride/5-bromo-4chloro-3-indolyl phosphate as a substrate for $3 \mathrm{~h}$ (to Plcb2 and Itpr3) or two overnights (to Calhm1). Stained images were obtained using a Nikon Eclipse 80i microscope (Nikon Instruments) equipped with a DXM1200C digital camera (Nikon).

For double-label fluorescence in situ hybridization, the fluorescence signals of the riboprobes were developed using an alkaline phosphatase-conjugated anti-digoxigenin antibody followed by the HNPP Fluorescent Detection set (Roche Diagnostics) and a biotin-conjugated anti-fluorescein antibody (Vector Laboratories, BA-0601, RRID:AB_2336069) followed by an avidinbiotin complex (Vector Laboratories), a TSA Biotin Tyramide Reagent (PerkinElmer), and an Alexa Fluor 488-conjugated streptavidin (Thermo Fisher Scientific). Fluorescence single-plane confocal images were acquired with a Leica TCS SP2 confocal microscope (Leica Microsystems). Optical confocal images were processed with Photoshop (Adobe Systems). For quantification of cells with fluorescence signals, taste buds on every 8,12 , or 16 sections of the FuP and soft palate from three mice were analyzed. For the frequencies of expression of $S \mathrm{kn}$ $1 a$ and Entpd2+Pkd2/1 in taste bud cells, sections were counterstained with 4',6-diamidino-2-phenylindole (DAPI). The ratios of $S k n-1 a$-expressing cells or Pkd2/1-expressing or Entpd2-expressing cells to the taste bud cells as judged from DAPI and DIC images were calculated using every 8 , 12 , or 16 sections of the FuP and soft palate of wild-type (WT; $n=3)$ and $S k n-1 a^{-/-}(n=3)$ mice.

For double-labeling of Calhm1 or ENaC $\alpha$ with other genes, fluorescence and chromogenic signals were developed as previously described (Taruno et al., 2013). Prehybridization, hybridization, and washing were performed at $65^{\circ} \mathrm{C}$ for any probes, and the fluorescence signals were first developed using a biotin-conjugated antifluorescein antibody (Vector Laboratories) followed by an avidin-biotin complex (Vector Laboratories), a TSA Biotin Tyramide Reagent (PerkinElmer), and an Alexa Fluor 488conjugated streptavidin (Thermo Fisher Scientific). After capturing the fluorescence signals with a Leica TCS SP2 confocal microscope (Leica Microsystems), the chromogenic signals of Calhm1 or ENaC $\alpha$ were detected using an alkaline phosphatase-conjugated anti-digoxigenin antibody and 4-nitro blue tetrazolium chloride/5-bromo4-chloro-3-indolyl phosphate. Stained images were obtained as described above. Fluorescence and stained images were processed with Photoshop (Adobe Systems). For quantification of cells with fluorescence and stained signals, taste buds on every 8,12 , or 16 sections of the FuP and soft palate from three mice were analyzed.

\section{Immunohistochemistry}

Immunohistochemical analyses using 4\% PFA-fixed sections were conducted as previously described (Ohmoto et al., 2008; Taruno et al., 2013). The sections were treated in a preheated target retrieval solution ( $\mathrm{pH}$ 9; Agilent Technologies) at $80^{\circ} \mathrm{C}$ for $20 \mathrm{~min}$ before blocking. Mouse anti-Itpr3 (1:1000, BD Biosciences, 610312, RRID: AB_397704), Rabbit antiGnat3 (1:1000, Santa Cruz Biotechnology, sc-395, RRID:AB 673678), anti-T1R3 (1:1000; Ohmoto et al., 2008), anti-Skn1a (1:1000, Santa Cruz, sc-330, RRID:AB_677443), and antidopa decarboxylase (Ddc; 1:2000, GeneTex, GTX30448, RRID:AB_367199) antibodies were used as primary antibodies. Alexa Fluor 488-conjugated goat anti-mouse lgG (1:500, Thermo Fisher Scientific, A-11 029, RRID:AB 2534088) and Alexa Fluor 555-conjugated goat anti-rabbit IgG (1:500, Thermo Fisher Scientific, A-21 429, RRID:AB_2535850) were used as secondary antibodies. Fluorescent images were acquired and processed as described above.

\section{Whole chorda tympani nerve recordings}

We investigated the electrophysiological response of the chorda tympani nerve in mice of the Skn-1a knock-out 
$\left(S k n-1 a^{--}\right)$and Calhm3 knock-out $\left(\mathrm{Calhm}^{-/-}\right)$strains, using C57BL/6J mice as WT controls (see above). The experimenters were blinded to the genotype of the mice during testing. The mice were anesthetized with an intraperitoneal injection of a mixture of $4.28 \mathrm{mg} / \mathrm{ml}$ ketamine, $0.86 \mathrm{mg} / \mathrm{ml}$ xylazine, and $0.14 \mathrm{mg} / \mathrm{ml}$ acepromazine in saline $(5 \mu \mathrm{l} / \mathrm{g}$ body weight). Anesthesia was maintained with additional injections. Each mouse was fixed with a head holder after its trachea was cannulated, and the chorda tympani nerve was dissected free from its junction with the lingual nerve near the tympanic bulla; then the nerve was cut and the central part was placed on a platinum wire recording electrode. An indifferent electrode touched the walls of the wound. Taste stimuli were delivered to the tongue with a computer-controlled open flow system under constant flow and temperature $\left(25^{\circ} \mathrm{C}\right)$ conditions. Each stimulation lasted for $30 \mathrm{~s}$ with a 60 -s rinse between stimulations. Care was taken to ensure that the flow was directed over the FuP. The nerve impulses were fed into a custom-made amplifier, monitored over a loudspeaker and with an oscilloscope, and recorded (PowerLab/sp4; $A D$ Instruments). The integrated response during stimulation was calculated by subtracting the area of nerve activity preceding the stimulation from that during stimulation. Thus, the data reflect the level of activity during the stimulation period. The responses to all compounds were expressed relative to the response to $0.1 \mathrm{M} \mathrm{NH}_{4} \mathrm{Cl}$, which is derived from solely sour taste cells (Oka et al., 2013), for each mouse as previously described (Matsumoto et al., 2011; Ma et al., 2018). The averages for each animal and group were calculated for the statistical analyses.

\section{Statistical analyses}

Data are shown as the mean \pm SEM. A Welch's $t$ test (for histochemical analyses) or repeated-measures twoway ANOVA (for gustatory nerve recordings) was used to determine the effects of genotype using Prism 6 software (GraphPad Software). When a significant interaction was detected between a genotype and a taste solution concentration, Tukey-Kramer multiple comparison tests were conducted to identify significant differences between pairs of mean values.

\section{Results}

Previous studies demonstrated that $S k n-1 a$ is necessary for the generation of sweet, umami, and bitter taste cells, and that Calhm1, Calhm3, and Trpm5 mRNAs are co-expressed only in Skn-1a-dependent taste cells in the CvP (Matsumoto et al., 2011; Ma et al., 2018). Intriguingly, Calhm 1 has been implicated in salty taste (Tordoff et al., 2014), whereas it has been suggested that $\mathrm{AS} \mathrm{NaCl}$ responses arise from cells that lack Trpm5 expression (Chandrashekar et al., 2010). Recent efforts to identify AS sodium taste cells in the FuP have produced conflicting results. For example, it was suggested that Calhm3 expressed in Skn-1a-dependent taste cells (Ma et al., 2018) is required for $\mathrm{AS} \mathrm{NaCl}$ responses (Nomura et al., 2020), whereas it has also been suggested that Skn-1a-deficient mice that do not express either Calhm1 or Calhm3 (Taruno et al., 2013; Ma et al., 2018) still exhibited AS
$\mathrm{NaCl}$ responses as much as a half of those of WT mice (Larson et al., 2020). To better understand the identity and molecular features of AS $\mathrm{NaCl}$-sensing taste (i.e., as sodium-taste) cells, we conducted in situ hybridization analyses in FuP taste buds where sodium-taste cells reside and soft palate and gustatory nerve recordings of the chorda tympani nerve innervating FuP taste buds.

\section{Taste cell gene expression in taste buds of FuP}

First, we asked whether CALHM and Trpm5 channel genes are always co-expressed in the same cells of FuP by double-fluorescence in situ hybridization using Calhm3 and Trpm5 as probes. In taste buds of FuP where the chorda tympani nerve innervates, Trpm5 signals were observed only in cells showing Calhm3 signals. However, $\sim 20 \%$ of Calhm $^{+}$cells did not generate Trpm5 signals (Fig. 1A). This result is in contrast to their complete co-expression in taste bud cells of the CvP (Ma et al., 2018). Accordingly, these data are consistent with previous findings that sodium taste is mediated by a taste cell subset distinct from sweet, umami, and bitter taste cells but nevertheless requires CALHM channel genes for neurotransmission (Chandrashekar et al., 2010; Tordoff et al., 2014; Nomura et al., 2020).

Then, we examined whether other genes encoding sweet, umami, and bitter taste signaling molecules are expressed in both the Trpm5 ${ }^{+}$and Trpm5 ${ }^{-}$taste cells. Of note, it has been suggested that sodium-taste cells do not require $\mathrm{Ca}^{2+}$ signaling evoked by phosphatidylinositol (PI) turnover, unlike Type II cells (Nomura et al., 2020). Surprisingly, in taste buds of the FuP, Plcb2 and Itpr3 were expressed in Trpm5 $5^{-}$cells and always co-expressed with Calhm3, whereas Gnat3 was expressed only in Trpm5 ${ }^{+}$taste cells (Fig. 1). These results strongly suggest that Calhm3-expressing taste cells can be classified into two subsets: those that are all positive (i.e., for the expression of Plcb2, Itpr3, Calhm3, Gnat3, and Trpm5) and those that are Plcb2 ${ }^{+}$Itpr3 ${ }^{+}$Calhm3 ${ }^{+}$Gnat3-Trpm5 ${ }^{-}$(hereafter referred to as Calhm $3^{+}$Trpm5 $5^{-}$cells in this study). In agreement, anti-Itpr3 and anti-Gnat3 antibodies identified Itpr3 ${ }^{+} \mathrm{Gnat}^{+}$and Itpr3 ${ }^{+} \mathrm{Gnat}^{-}$cells in taste buds of the FuP, whereas in taste buds of the CvP, where cells expressing Gnat3 and/or Tas1r3 are identical to Trpm5 ${ }^{+}$ cells (Ohmoto et al., 2011), Itpr $3^{+}$cells are always positive for Gnat3 and/or T1R3 (Extended Data Fig. 1-1A). The ratios of Itpr3 ${ }^{+} \mathrm{Gnat3}^{+}$and Itpr3 ${ }^{+}$Gnat3 ${ }^{-}$cells to total Itpr3 ${ }^{+}$ cells (Itpr ${ }^{+} \mathrm{Gnat}^{+}, 77.8 \%$; Itpr3 ${ }^{+}$Gnat3 ${ }^{-}$cells, $22.2 \%$ ) are comparable to those of Calhm $3^{+}$Trpm5 $^{+}$(78.3\%) and Calhm3 ${ }^{+}$Trpm5 $^{-}(21.7 \%)$ cells to Calhm3 ${ }^{+}$cells (Fig. 1; Extended Data Fig. 1-1A). Consistent with mRNA expression profiles, Itpr3-immunoreactive signals were observed in Skn-1 $\mathrm{a}^{+}$cells but not in cells positive for sour taste cell marker Ddc (i.e., $\mathrm{DDC}^{+}$cells; Extended Data Fig. 1-1B). Interestingly, cells exhibiting similar molecular features were also detected in taste buds of soft palate that are innervated by the greater superficial petrosal nerves (Extended Data Figs. 1-1, 1-2). Accordingly, the Calhm $3^{+}$Trpm5 $5^{-}$cells found in taste buds in the FuP and soft palate but not in the CvP are predicted to be involved in a taste that is specifically transmitted by the 


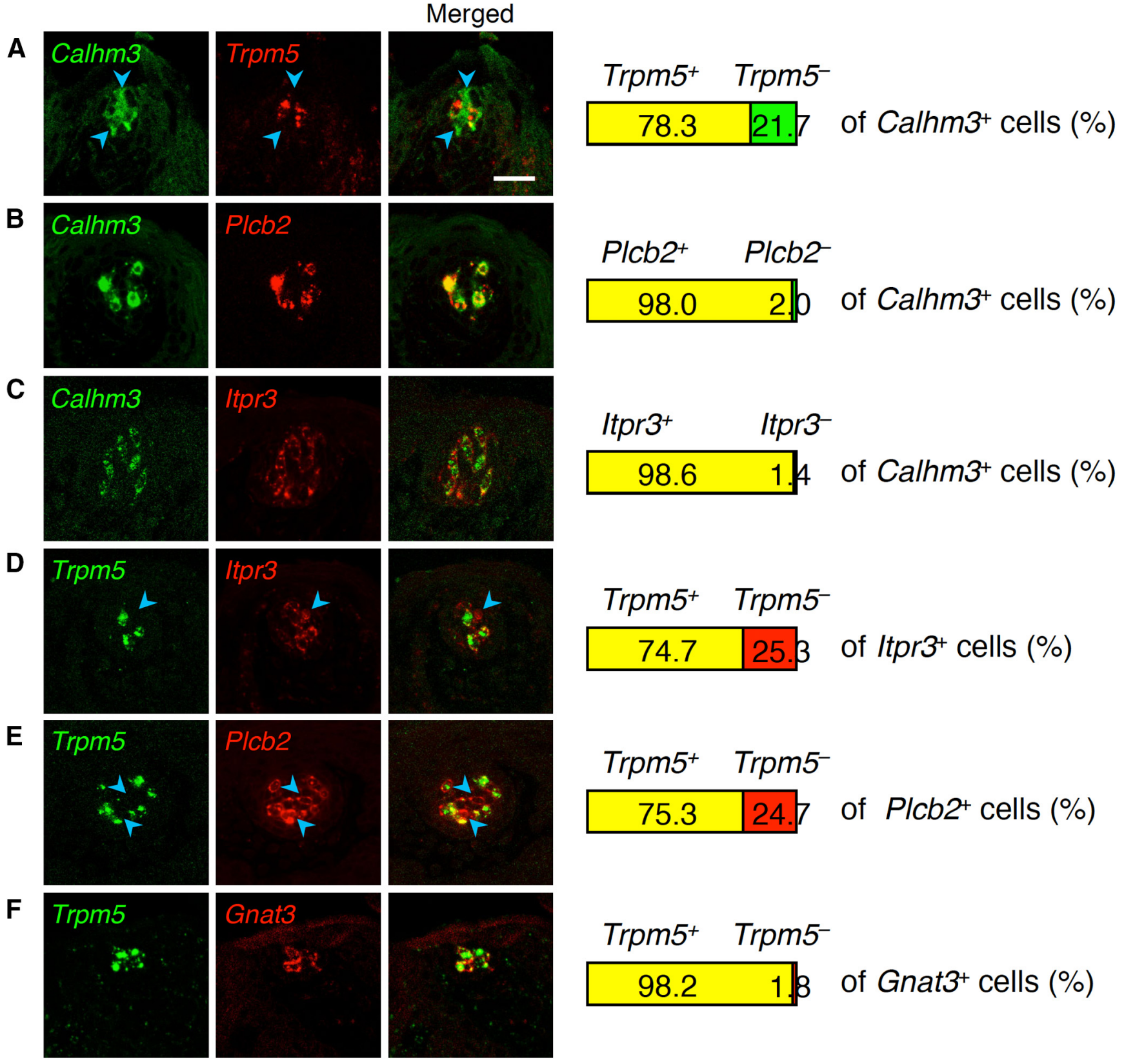

Figure 1. Expression of taste cell genes in taste buds in FuP. Double-fluorescence in situ hybridization was performed to study expression of genes required for sweet, umami, bitter, or salty taste perception. Numbers of cells showing signals were counted, and the ratios of cells positive and negative for one gene $(\boldsymbol{A}-\boldsymbol{C}$, middle images; $\boldsymbol{D}-\boldsymbol{F}, \operatorname{Trpm5})$ to the total population of cells positive for the other gene $(\boldsymbol{A}-\boldsymbol{C}, \mathbf{C a l h m 3} ; \boldsymbol{D}-\boldsymbol{F}$, middle image) are shown at the right $(n=3)$. $\boldsymbol{A}-\boldsymbol{C}, \operatorname{Trpm} 5(\boldsymbol{A})$, Plcb2 $(\boldsymbol{B})$, and Itpr3 $(\boldsymbol{C})$ compared with Calhm3. D-F, Itpr3 (D), Plcb2 (E), and Gnat3 $(\boldsymbol{F})$ compared with Trpm5. Blue arrowheads indicate Calhm3, Itpr3, or Plcb2 single-positive cells. Scale bar: $25 \mu \mathrm{m}$.

chorda tympani and greater superficial petrosal nerves. Because neurophysiological studies in rats suggest the existence of $\mathrm{AS} \mathrm{NaCl-sensing} \mathrm{taste} \mathrm{cells} \mathrm{in} \mathrm{the} \mathrm{greater}$ superficial petrosal nerve-innervated taste buds in soft palate (Harada et al., 1997; Sollars and Hill, 1998), the Calhm3 ${ }^{+} \mathrm{Trpm}^{-}$cells are likely to be sodium-taste cells in the FuP and soft palate taste buds.

In taste buds of Skn-1a-deficient mice, Calhm3 expression was not detected in the FuP, palate, or CvP (Ma et al., 2018). Similarly, the expression of Plcb2, Itpr3, and
Calhm1 was not detected in taste buds in any gustatory areas (Fig. 2; Extended Data Fig. 2-1; Matsumoto et al., 2011; Taruno et al., 2013). Notably, Plcb2, Itpr3, and Calhm3 were always co-expressed with $S k n-1 a$, and the frequencies of $S k n-1 a$ signal are comparable to those of Plcb2, Itpr3, and Calhm3 signals (Fig. 3; Extended Data Fig. 3-1). Consistent with the relationship of expression of Trpm5 and Plcb2, Itpr3, and Calhm3, Trpm5 signals were detected in $77.0 \pm 3.2 \%$ and $87.2 \pm 3.2 \%$ of $S k n-1 a^{+}$ cells in the FuP and soft palate, respectively (Fig. 3; 


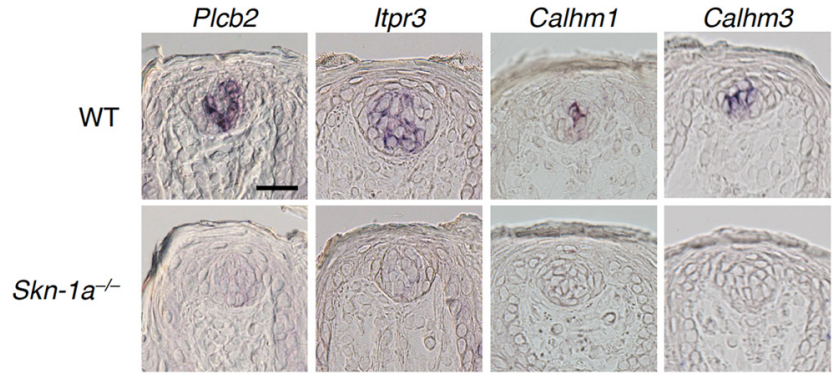

Figure 2. Requirement of $S k n-1 a$ for the expression of Plcb2, Itpr3, Calhm1, and Calhm3 in taste buds in FuP. In situ hybridization analyses revealed that the expression of Plcb2, Itpr3, Calhm1, and Calhm3 observed in WT mice (top) were not detected in taste buds in $S k n-1 a^{-/-}$mice (bottom). Scale bar: $25 \mu \mathrm{m}$.

Extended Data Fig. 3-1). These results indicate that Skn$1 \mathrm{a}^{+}$cells in the FuP and soft palate can be classified into the same two differentiated cell subsets as Calhm3-expressing taste cells: all positive and Calhm $3^{+} \mathrm{Trpm}^{-}$subsets. The somewhat greater number of cells expressing Skn-1a than Plcb2, Itpr3, and Calhm3 can be explained by $S k n-1 a$ expression in putative precursor cells in taste buds in addition to the differentiated taste cells such as sweet, umami, and bitter taste cells.

\section{Skn-1a is required for generation of Calhm $3^{+} \mathrm{Trpm}_{5}^{-}$ cells}

Skn-1a is required for the generation of Type II cells (based on morphologic classification) that express Trpm5 and Plcb2 and mediate sweet, umami, and bitter tastes (Matsumoto et al., 2011). The Calhm3 ${ }^{+}$Trpm5 $^{-}$cells also express Skn-1a (Figs. 2, 3; Extended Data Figs. 2-1, 3-1). Thus, we asked whether $S k n-1 a$ is required for the generation of Calhm3 ${ }^{+} \mathrm{Trpm}^{-}$cells or simply for the expression of Plcb2, Itpr3, and Calhm3 in the Calhm3 ${ }^{+} \mathrm{Trpm}^{-}$cells independent of their generation. For this, we employed double-label fluorescence in situ hybridization analyses using probes to detect $S k n-1 a^{+}$and $S k n-1 a^{-}$taste bud cells. Because $S k n-1 a^{-}$taste bud cells are comprised predominantly of Type I putative non-sensory cells and Type III sour taste cells, we used probes for Entpd2 that is expressed in Type I cells and for Pkd2/1 that is expressed in sour taste cells to identify $S k n-1 a^{-}$cells. In WT mice, FuP taste buds contained $66.9 \pm 2.4 \%$ Skn-1a- (i.e., Entpd2$P k d 2 / 1$ mixed probe-positive) cells and $29.9 \pm 3.0 \%$ Skn$1 \mathrm{a}^{+}$cells (Fig. 4). In the Skn-1a-deficient mice, the taste
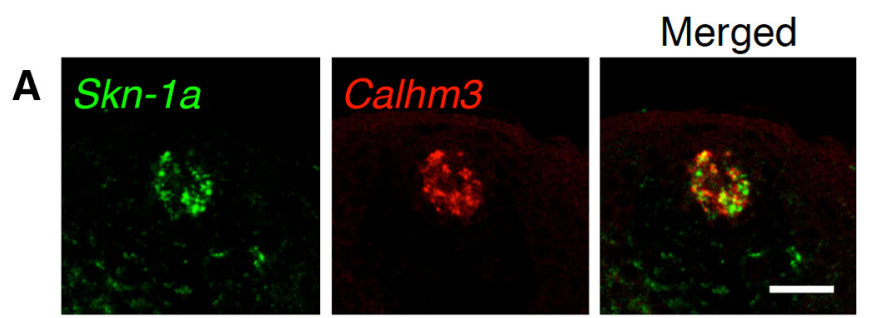

B
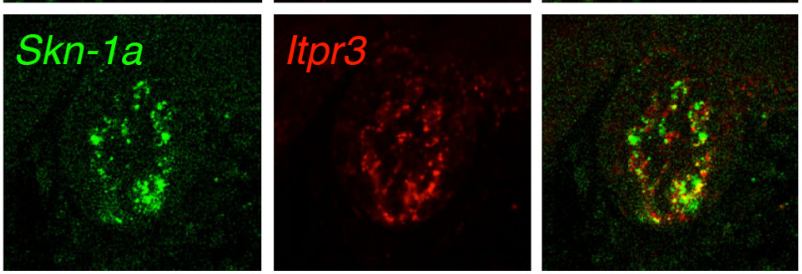

\section{Calhm3 $^{+}$Calhm3-}

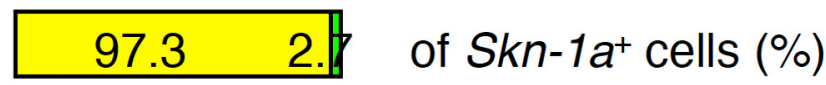

C
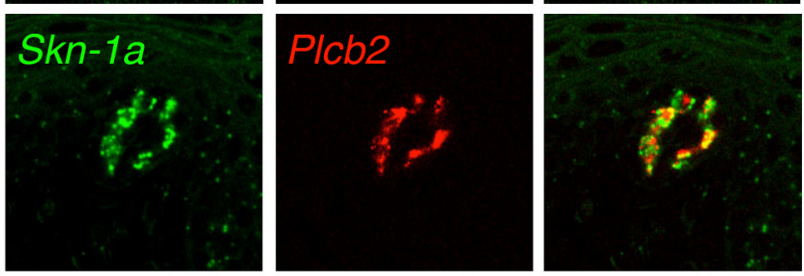

D
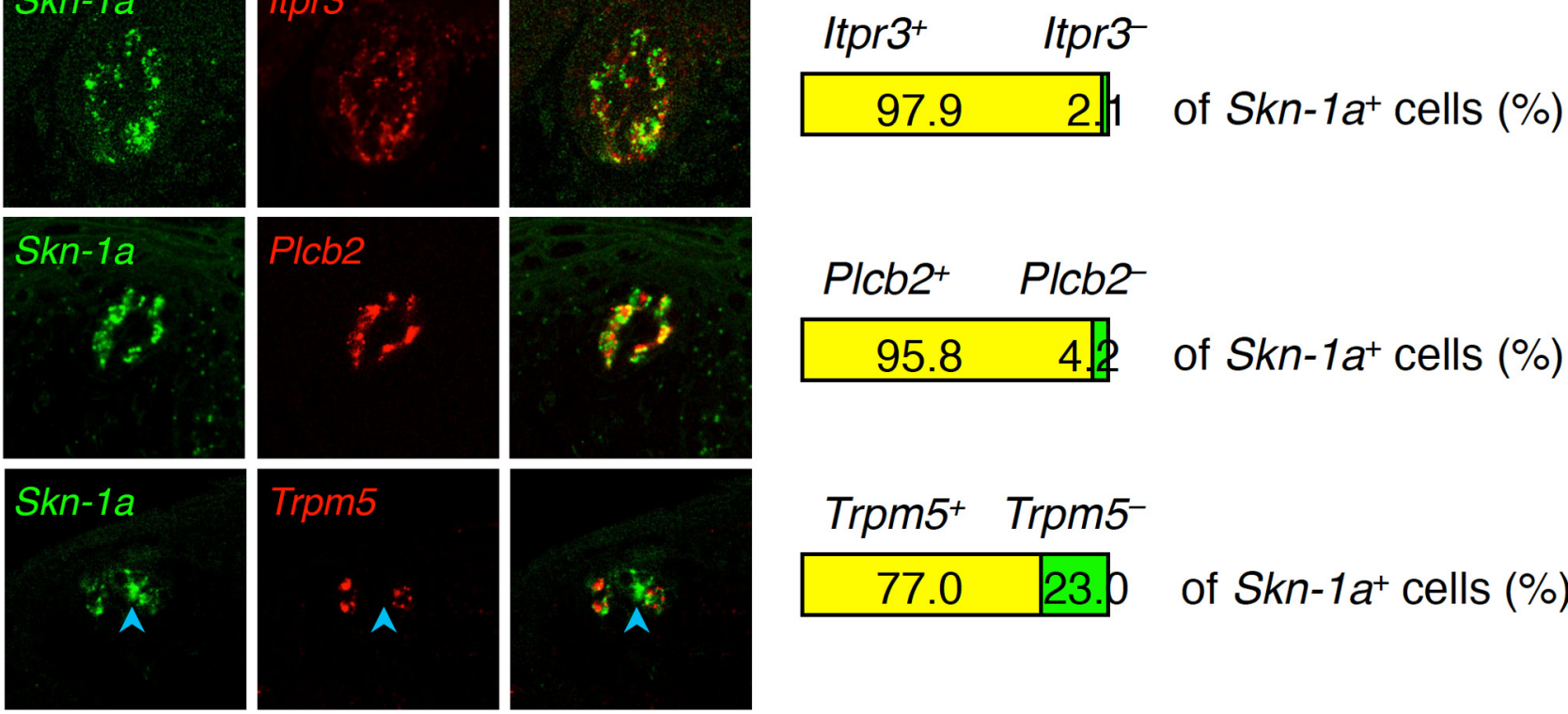

$\mathrm{Plcb2}^{+} \quad \mathrm{Plcb2}$

$95.8 \quad 4 \$$ of $S k n-1 a^{+}$cells (\%)

Trpm5 $^{+}$Trpm5

\begin{tabular}{l|l}
77.0 & 23.0 \\
\end{tabular}

Figure 3. Co-expression of Skn-1a with taste cell genes in taste buds in FuP. Double-fluorescence in situ hybridization was performed to study the relationship of expression of Skn-1a with Calhm3 (A), Itpr3 (B), Plcb2 (C), and Trpm5 (D). Numbers of cells showing signals were counted, and the ratios of cells positive and negative for Calhm3 (A), Itpr3 (B), Plcb2 (C), and Trpm5 (D) to the total population of cells positive for $S k n-1 a$ are shown at the right $(n=3)$. Blue arrowheads indicate Skn-1a single-positive cells. Scale bar: $25 \mu \mathrm{m}$. 


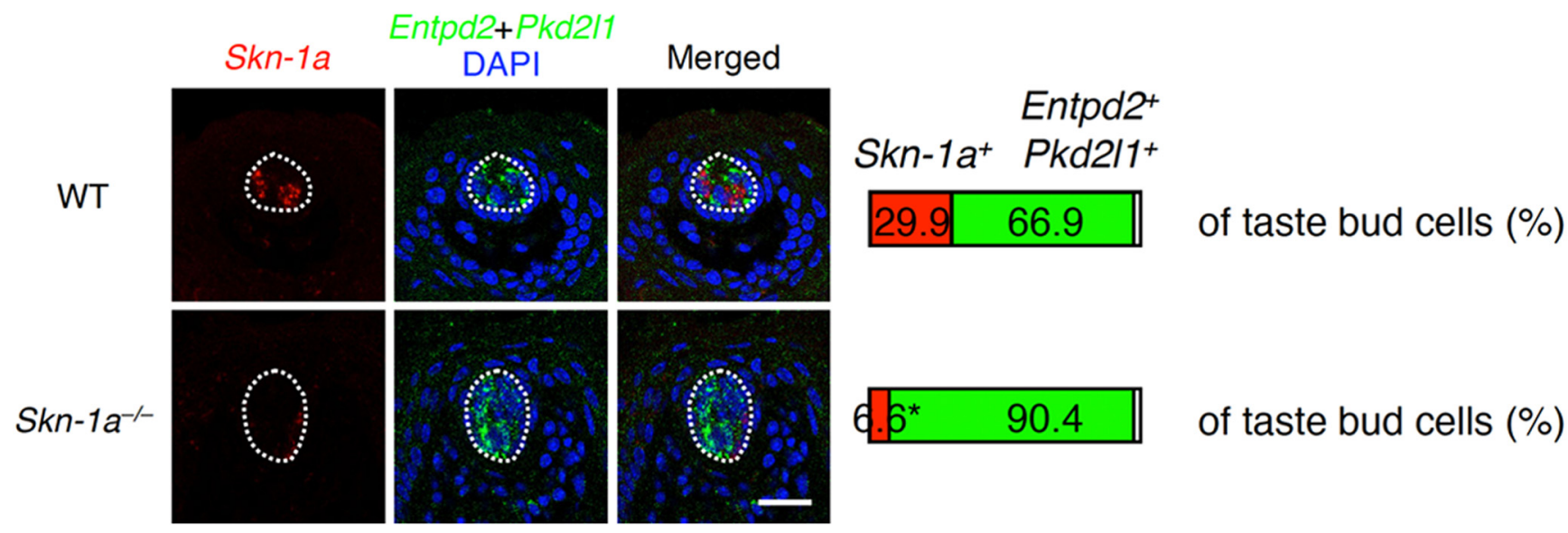

Figure 4. Disappearance of $S k n-1 a-d e p e n d e n t$ taste bud cells by $S k n-1 a$ deficiency. Populations of $S k n-1 a^{+}$and $S k n-1 a^{-}$cells (i.e., positive to a mixed probe to Entpd2 and Pkd2/1) in taste buds in FuP were quantified by double-fluorescence in situ hybridization analyses. Taste bud profiles are outlined by broken white line. Asterisk indicates the ratio expressing mutant Skn-1a mRNA. The decrease of the $S k n-1 a^{+}$cell population was statistically evaluated by Welch's $t$ test: $p=0.0056$. Scale bar: $25 \mu \mathrm{m}$.

buds contained $90.4 \pm 1.1 \%$ Skn-1a- (i.e., Entpd2 and $P k d 2 / 1$ mixed probe-positive) cells, and $6.6 \pm 1.8 \%$ Skn-1a+ cells ( $p=0.0056$; Fig. 4). Skn-1a-deficient mice express mutant $S k n-1 a$ mRNA in basal cells, putatively postmitotic taste bud precursor cells (Matsumoto et al., 2011), that likely accounts for the residual $S k n-1 a$ mRNA signal. These results demonstrate that Skn-1adeficient mice lack all $S k n-1 a^{+}$differentiated cells including Calhm $3^{+}$Trpm5 $5^{-}$cells. Similar results were observed in taste buds of soft palate $(32.4 \pm 0.7 \%$ and $5.5 \pm 1.1 \%$ Skn-1a ${ }^{+}$cells in WT and Skn-1a-deficient mice, respectively, $p=0.0001$; Extended Data Fig. 4-1). Thus, like sweet, umami, and bitter Type II taste cells, Calhm $3^{+}$Trpm $^{-}$cells also require $S k n-1 a$ for their generation.

\section{Skn-1a is required for gustatory nerve responses to $\mathrm{NaCl}$}

Because the existence of Calhm3 ${ }^{+}$cells depends on $S k n-1 a$, the phenotype by Calhm3 deficiency in gustatory nerve responses is expected to be recapitulated in the Skn-1a-deficient mice. However, recent findings by two groups presented conflicting results, although they both showed the requirement, at least in part, of Calhm3 and Skn-1a in the AS NaCl responses of chorda tympani nerves (Larson et al., 2020; Nomura et al., 2020). We interrogated whether Skn-1a and Calhm3 are equally required for $\mathrm{NaCl}$ taste by recording chorda tympani nerve responses. Genetic deletion of $S k n-1 a$ reduced responses to 300 and $1000 \mathrm{mM} \mathrm{NaCl}(p<0.0001)$. AS responses were eliminated at all concentrations over $100 \mathrm{mM}(p<0.0001$ for 100 , 300 , and $1000 \mathrm{mM})$, whereas Al responses were diminished only at $1000 \mathrm{mM}(p<0.0001$; Fig. $5 A, B$; Table 2). The decrease of Al responses in the Skn-1a-deficient mice can most likely be accounted for by the absence of bitter taste cells in these mice that contribute to the taste of high salt concentrations (Matsumoto et al., 2011; Oka et al., 2013). These results demonstrate that both $\mathrm{AS}$ and $\mathrm{AI} \mathrm{NaCl}$ tastes are largely mediated by $S k n-1 a$-dependent taste bud cells. Consistent with this, AS responses of the chorda tympani nerve to $\mathrm{NaCl}$ were eliminated in Calhm3-deficient mice (Fig. 5C), and Calhm3 is involved in Al chorda tympani nerve responses in bitter taste cells (Ma et al., 2018). Together, our results indicate that the Calhm $3^{+} \mathrm{Trpm} 5^{-}$ cells mediate sodium taste, whereas sour taste cells together with bitter taste cells mediate Al salt taste, as previously demonstrated (Oka et al., 2013). These results support the finding by Nomura et al. (2020) and are partially consistent with the results by Larson et al. (2020), with regard to $\mathrm{AS} \mathrm{NaCl}$ responses. Furthermore, they question the claim that $\mathrm{Al} \mathrm{NaCl}$ taste is mediated by Type II cells including sweet taste cells (Roebber et al., 2019).

\section{Calhm3 ${ }^{+} \mathrm{Trpm}^{-}$cells express $\mathrm{ENaC} \alpha$}

Sodium taste deficiency by the conditional deletion of $E N a C \alpha$ in Calhm $3^{+}$taste cells (Nomura et al., 2020) and the lack of Trpm5 expression in the putative $\mathrm{ENaC} \alpha^{+}$cells identified by a reporter expression in transgenic mice (Chandrashekar et al., 2010) suggest that $E N a C \alpha$ is expressed in Calhm $3^{+} \mathrm{Trpm}^{-}$cells. However, it was not confirmed that the reporter recapitulates the $E \mathrm{NaC} \alpha$ expression in the FuP and/or soft palate, since reginal expression may be regulated by a distinct enhancer that may not be included in the transgene, as shown for Shh expression (Sagai et al., 2009). Thus, we tested the possibility that $E N a C \alpha$ is expressed in Calhm3 ${ }^{+} \mathrm{Trpm}^{-}$ cells.

Because $E N a C \alpha$ signals in taste buds in the FuP were too weak to detect by double-fluorescence in situ hybridization, we employed long-term signal development using chromogenic substrate to detect $E N a C \alpha$ expression in combination with fluorescence signal detection for other taste cell genes. This method was previously shown to be as efficacious as double-fluorescence in situ hybridization in an analysis of the relationship of weak Calhm1 expression with taste cell marker gene expression (Taruno et al., 2013). Employing this method, we found that Calhm1 was always co-expressed with Calhm3 (Extended Data Fig. 
A

Wild type

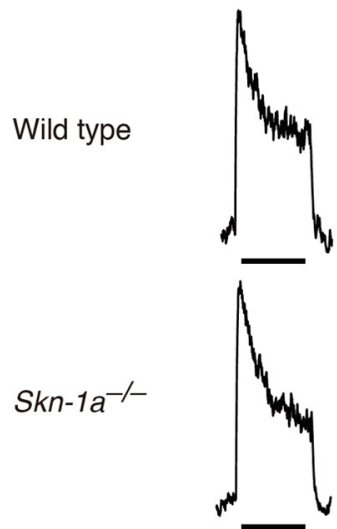

$\mathrm{NH}_{4} \mathrm{Cl}$

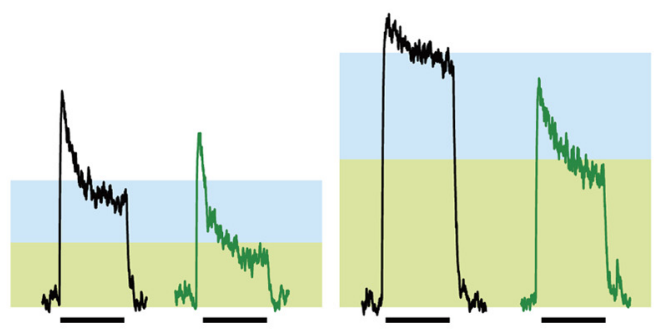

B
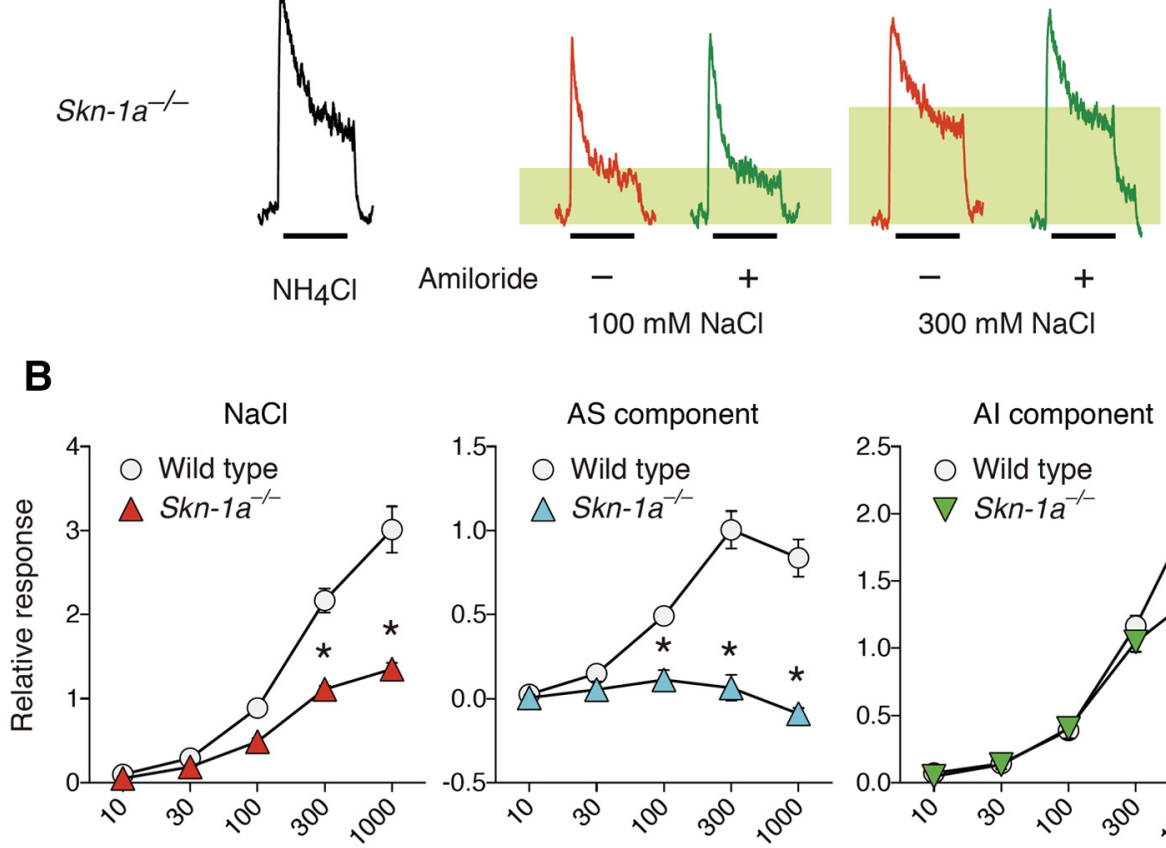

$100 \mathrm{mM} \mathrm{NaCl}$

$300 \mathrm{mM} \mathrm{NaCl}$

C

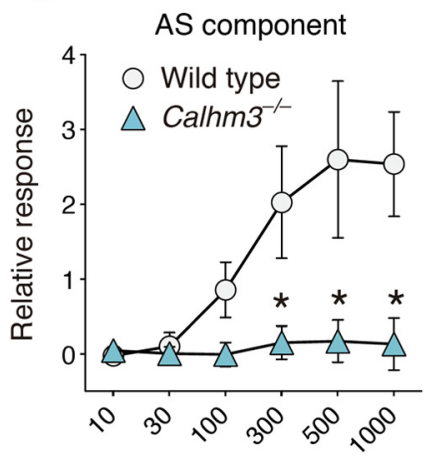

Figure 5. Skn-1a deficiency extinguishes AS chorda tympani nerve responses to $\mathrm{NaCl}$. $\boldsymbol{A}$, Representative charts of chorda tympani nerve responses of WT and $S k n-1 a^{-/-}$mice to $\mathrm{NaCl}$ in the presence (green traces) or absence of $100 \mu \mathrm{m}$ amiloride. Shaded rectangles depict the AS (blue) and $\mathrm{Al}$ (green) components in response to $\mathrm{NaCl}$. The bars under the traces show the duration (30 s) of the taste stimulus. $\boldsymbol{B}, \boldsymbol{C}$, Whole chorda tympani nerve responses of $S k n-1 a^{-/-}(n=3)$ and WT $(n=4)$ mice $(B)$ and Calhm3 $3^{-/-}(n=6)$ and WT $(n=5)$ mice $(\boldsymbol{C})$ to $\mathrm{NaCl}$. AS salt responses (AS component; $\boldsymbol{B}$, middle) were measured by subtracting the Al response (Al component; $\boldsymbol{B}$, right) from the whole salt response $(\boldsymbol{B}$, left). Significance was assessed by a repeated-measures two-way ANOVA and the Tukey-Kramer test: ${ }^{*} p<0.05$. Data are expressed as the mean \pm SEM; where error bars are not visible, they are smaller than the symbol depicting the mean. For details, see Table 2.

6-1), consistent with the same phenotypes of the knockouts in gustatory nerve recordings (Fig. 5; Taruno et al., 2013; Tordoff et al., 2014; Ma et al., 2018; Nomura et al., 2020). Similarly, we observed partial overlap of $E N a C \alpha$ with Skn-1a and Calhm3 localizations (Fig. 6A,B; Extended
Data Fig. 6-2A,B; Table 3). Although fluorescence signals of a cell may possibly overlap with chromogenic signals of another cell located above or below of fluorescence sig$\mathrm{nal}^{+}$cell, we never observed any overlap of $E N a C \alpha$ with Trpm5 in the FuP or soft palate (Fig. 6C; Extended Data 
Table 2: Summary of statistical analyses of chorda tympani responses to $\mathrm{NaCl}$

\begin{tabular}{|c|c|c|c|c|c|c|c|}
\hline Component & Genotype & & Concentration & & Interaction & & $\begin{array}{l}\text { Concentrations differing } \\
\text { significantly with } p \text { value }\end{array}$ \\
\hline \multicolumn{8}{|l|}{ Skn-1a KO vs WT } \\
\hline Whole to $\mathrm{NaCl}$ & $F_{(1,5)}=42.156$ & $p=0.0013$ & $F_{(4,20)}=138.85$ & $p<0.0001$ & $F_{(4,20)}=19.995$ & $p<0.0001$ & $\begin{array}{l}300 \mathrm{mM}(p<0.0001) \\
1000 \mathrm{mM}(p<0.0001)\end{array}$ \\
\hline AS & $F_{(1,5)}=44.941$ & $p=0.0011$ & $F_{(4,20)}=34.275$ & $p<0.0001$ & $F_{(4,20)}=38.247$ & $p<0.0001$ & $\begin{array}{l}100 \mathrm{mM}(p=0.0149) \\
300 \mathrm{mM}(p<0.0001) \\
1000 \mathrm{mM}(p<0.0001)\end{array}$ \\
\hline $\mathrm{Al}$ & $F_{(1,5)}=10.019$ & $p=0.0249$ & $F_{(4,20)}=174.55$ & $p<0.0001$ & $F_{(4,20)}=8.0069$ & $p=0.0005$ & $1000 \mathrm{mM}(p<0.0001)$ \\
\hline \multicolumn{8}{|l|}{ Calhm3 KO vs WT } \\
\hline AS & $F_{(1,9)}=35.852$ & $p=0.0002$ & $F_{(5,45)}=47.097$ & $p<0.0001$ & $F_{(5,45)}=37.400$ & $p<0.0001$ & $\begin{array}{l}300 \mathrm{mM}(p<0.0001) \\
500 \mathrm{mM}(p<0.0001) \\
1000 \mathrm{mM}(p<0.0001)\end{array}$ \\
\hline
\end{tabular}

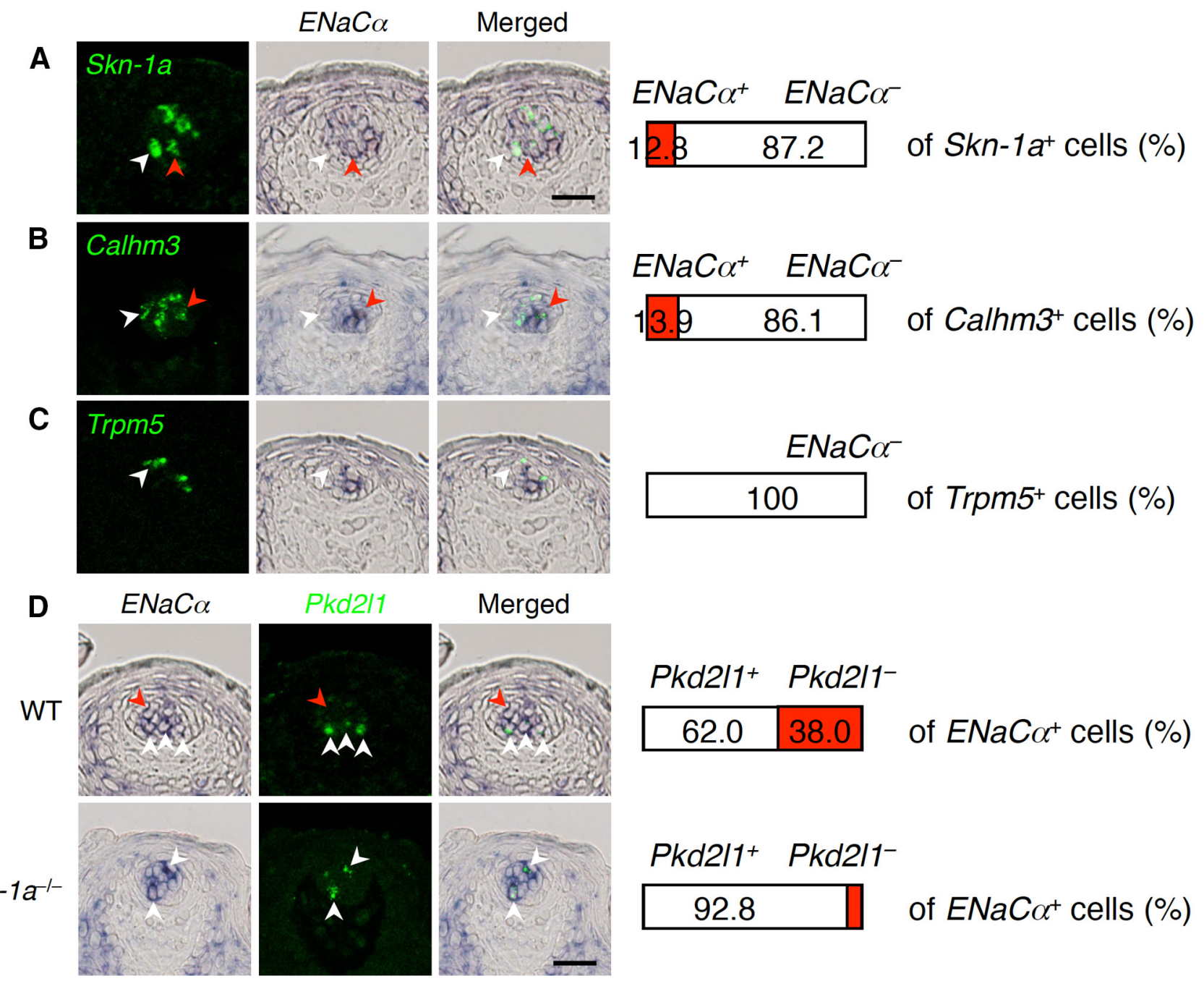

Figure 6. ENaC $\alpha$ expression in Calhm $3^{+} \mathrm{Trpm}^{-}$sodium-taste cells in FuP. Double-labeling in situ hybridization was performed to study expression of $E N a C \alpha$ in Calhm3 ${ }^{+} \mathrm{Trpm}^{-}$sodium-taste cells. $\boldsymbol{A}-\boldsymbol{C}, E N a C \alpha$ expression and that of $S k n-1 a(\boldsymbol{A}), \mathrm{Calhm} 3(\boldsymbol{B})$, and Trpm5 $(\boldsymbol{C})$. Numbers of cells showing signals were counted, and the ratios of cells positive and negative for ENaC $\alpha$ (middle images) to the total population of cells positive for the gene (left images) are shown at the right $(n=3)$. White arrowheads indicate Skn-1a, Calhm3, or Trpm5 single-positive cells, and red arrowheads indicate cells co-expressing ENaC $\alpha$ and Skn-1a, Calhm3, or Trpm5. D, Robust decrease of ENaC $\alpha$-expression in non-sour taste cells by $S k n-1 a$ deficiency in taste buds. Populations of $P k d 2 / 1^{+}$and $P k d 2 / 1^{-}$cells in ENaC $\alpha$-expressing cells were quantified by double-labeling in situ hybridization analyses. White and red arrowheads indicate representative $\mathrm{Pkd} 2 / 1^{+} \mathrm{ENaC} \alpha^{+}$and $\mathrm{Pkd} 2 / 1^{-} \mathrm{ENaC} \alpha^{+}$cells, respectively. Decrease of the $P \mathrm{kd} 2 / 1^{-} \mathrm{ENaC} \alpha^{+}$cell population was evaluated by Welch's $t$ test: $p=0.0422$. Scale bars: $25 \mu \mathrm{m}$. 
Table 3: Details of double-label in situ hybridization analyses for $E \mathrm{NaC} \alpha$ with taste cell marker genes

\begin{tabular}{|c|c|c|c|c|}
\hline Tissue & Mouse & $\begin{array}{l}\text { Marker } \\
\text { gene }\end{array}$ & $\begin{array}{l}\text { No. of } \\
\text { taste buds }\end{array}$ & Ratio $(\%)^{*}$ \\
\hline FuP & $\begin{array}{l}\mathrm{B} 6, n=3 \\
\mathrm{~B} 6, n=3 \\
\mathrm{~B} 6, n=3 \\
\mathrm{~B} 6, n=3 \\
\text { Skn-1a-1- } n=3\end{array}$ & $\begin{array}{l}\text { Skn-1a } \\
\text { Calhm3 } \\
\text { Trpm5 } \\
\text { Pkd2/1 } \\
\text { Pkd2/1 }\end{array}$ & $\begin{array}{l}40 \\
25 \\
27 \\
20 \\
27\end{array}$ & $\begin{array}{l}12.8 \pm 2.2 \\
13.9 \pm 3.2 \\
0 \\
38.0 \pm 7.2 \\
7.2 \pm 2.0\end{array}$ \\
\hline Palate & $\begin{array}{l}\mathrm{B} 6, n=3 \\
\mathrm{~B} 6, n=3 \\
\mathrm{~B} 6, n=3 \\
\mathrm{~B} 6, n=3 \\
\text { Skn-1a-1- } n=3\end{array}$ & $\begin{array}{l}\text { Skn-1a } \\
\text { Calhm3 } \\
\text { Trpm5 } \\
\text { Pkd2/1 } \\
\text { Pkd2/1 }\end{array}$ & $\begin{array}{l}32 \\
28 \\
25 \\
22 \\
39\end{array}$ & $\begin{array}{l}13.0 \pm 4.7 \\
8.8 \pm 0.6 \\
0 \\
44.5 \pm 3.0 \\
2.9 \pm 1.7\end{array}$ \\
\hline
\end{tabular}

Double-positive cells to marker gene-positive cells ( $S k n-1 a$, Calhm3, and Trpm5) or to $P k d 2 / 1^{-} E N a C \alpha^{+}$cells to $E N a C \alpha^{+}$cells.

Fig. 6-2C; Table 3), strongly suggesting that $E N a C \alpha$ and Trpm5 are not co-expressed in any taste cells. In addition, $E N a C \alpha$ expression was detected in both sour and nonsour taste cells (Fig. 6D), consistent with previous findings in transgenic mice (Chandrashekar et al., 2010) but incompatible with a previous single cell-PCR analysis (Yoshida et al., 2009). The $E N a C \alpha$ expression in nonsour taste cells was absent in Skn-1a-deficient mice (in FuP, $p=0.0422$; in soft palate, $p=0.0009$; Fig. 6; Extended Data Fig. 6-2; Table 3). These results indicate that Skn-1a-dependent Calhm3 ${ }^{+}$Trpm5 $^{-}$cells express $E N a C \alpha$ and serve as sodium-taste cells.

\section{Discussion}

The results of the present study demonstrate that sodium-taste cells and Type II sweet, umami, and bitter taste cells have shared molecular expression features, and a similar reliance on $S k n-1 a$ for their generation. These findings advance our understanding of the molecular mechanisms of taste cell differentiation, provide new insights into classification of taste cell lineage, and reveal a cellular mechanism that elicits salt taste.

\section{Cellular mechanism of taste by $\mathrm{NaCl}$}

Salts are dissolved in saliva, and either cations or anions could activate different taste cells independently. In case of $\mathrm{NaCl}, \mathrm{Na}^{+}$activates $\mathrm{ENaC} \alpha$-mediated AS mechanisms in a specific population of taste cells characterized by their ENaC $\alpha^{+}$Pkd2/1-Trpm5 ${ }^{-}$expression profile (Chandrashekar et al., 2010). Although it has been suggested that these AS salt taste cells do not possess voltage-gated $\mathrm{Na}^{+}$currents (Vandenbeuch et al., 2008), several studies have demonstrated that sodium-taste cells fire $\mathrm{Na}^{+}$action potentials (Bigiani and Cuoghi, 2007; Yoshida et al., 2009; Nomura et al., 2020) and that they are responsible for the avidity to $\mathrm{NaCl}$ (Chandrashekar et al., 2010; Nomura et al., 2020). They are most likely sensory cells.

Various chloride salts are sensed by yet-to-be identified Al mechanisms that may reside in sour and bitter taste cells (Oka et al., 2013) or sweet and bitter taste cells (Roebber et al., 2019). If Al salt taste resides in only sweet and bitter taste cells, chorda tympani nerve responses to $\mathrm{NaCl}$ in mice deficient in Calhm1, Calhm3, and Skn-1a should be absent over all concentrations. However, chorda tympani nerve responses to $\mathrm{NaCl}$ in these mice are comparable to those of WT mice except at very high concentrations (Fig. 5; Tordoff et al., 2014; Ma et al., 2018).

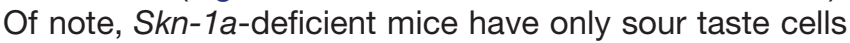
as sensory cells, and retain Al salt taste, demonstrating that the Al mechanism resides at least in part in sour taste cells. Consistent with this, Car4, which is expressed specifically in sour taste cells in taste buds, is involved in sensing a variety of chloride salts, although the mechanisms are unclear (Oka et al., 2013). Bitter taste cells have also been implicated in aversive salt taste (Oka et al., 2013). Mice deficient in any intracellular bitter signal transduction pathway molecule including Gnat3, PLC $\beta 2$, Trpm5, CALHM1, and CALHM3 exhibit deficits in neural or behavioral responses to high salt concentrations (Dotson et al., 2005; Glendinning et al., 2005; Oka et al., 2013; Taruno et al., 2013; Ma et al., 2018). It is possible that T2R bitter receptors associated with Gnat3 respond to chloride salts and trigger the bitter receptor downstream intracellular signal transduction pathway. Of note, human TAS2R7 serves as metallic cation receptor (Behrens et al., 2019; Wang et al., 2019). It is interesting to speculate that specific receptors for $\mathrm{Cl}^{-}$exist in sour and bitter taste cells that respond to various chloride salts.

\section{Intracellular signal transduction of sodium taste}

Our results suggest that taste bud cells in the FuP with the $E N a C \alpha^{+} P k d 2 / 1^{-}$Trpm5 $5^{-}$expression profile function as taste receptor cells responsible for sensing $\mathrm{Na}^{+}$ (Chandrashekar et al., 2010). Similar to other tastes, $\mathrm{NaCl}$ taste involves ATP release in neurotransmission (Finger et al., 2005), and deficiencies of Calhm 1 and Calhm3 encoding functional components of the ATPrelease channel eliminate AS salt responses (Fig. 5; Tordoff et al., 2014; Nomura et al., 2020). Sodium-taste cells also express Plcb2 and Itpr3 (Fig. 1), both of which are involved in the increases of intracellular $\left[\mathrm{Ca}^{2+}\right]$ in sweet, umami, and bitter Type II taste cells (Zhang et al., 2003). However, unlike their involvement in Type II cells, neither PLC $\beta 2$ nor $\mathrm{IP}_{3} \mathrm{R} 3$ is involved in the perception of $\mathrm{NaCl}$ (Zhang et al., 2003; Hisatsune et al., 2007; Tordoff and Ellis, 2013), consistent with recent findings that sodium-taste cells fire action potentials without increases of intracellular $\left[\mathrm{Ca}^{2+}\right.$ ] (Nomura et al., 2020). The roles of $P L C \beta 2$ and $I_{3} R 3$ in sodium-taste cells remain to be determined. Although sodium-taste cells lack expression of Gnat3 and Trpm5, their expression of Plcb2 and Itpr3 in sodium-taste cells may suggest that they express yet-to-be-identified $\mathrm{G}$ protein-coupled receptor (GPCR), G proteins, and cation channels (possibly $\mathrm{Ca}^{2+}$-dependent monovalent cation channels like Trpm5). It is therefore of some interest to understand the transcriptome of sodium-taste cells.

\section{Sodium-taste cells and the morphologic classification of taste bud cells}

Skn-1a regulates the differentiation of sweet, umami, and bitter taste cells and extra-oral taste cell-like 
chemosensory cells such as brush cells in the airways, urethra, and auditory tube. Like taste cells, those chemosensory cells express taste GPCRs (i.e., T1Rs and/or T2Rs), Gnat3, PLC $\beta 2$, and Trpm5 (Finger et al., 2003; Ohmoto et al., 2008; Krasteva et al., 2011, 2012; Matsumoto et al., 2011; Deckmann et al., 2014; Panneck et al., 2014; Yamashita et al., 2017). On the other hand, microvillous cells in the main olfactory epithelium have little similarity to taste and taste cell-like chemosensory cells with regard to molecular feature: they express only Trpm5 but not mRNA of taste GPCRs, Gnat3, or PLC $\beta 2$ (Yamaguchi et al., 2014), although immunoreactivities to Gnat3 and PLC $\beta 2$ were somehow detected (Genovese and Tizzano, 2018). Although neither intestinal tuft cells nor olfactory microvillous cells express taste GPCRs, the former express another GPCR, Sucnr1, and are involved in sensing chemical succinate, and the latter likely detect odor chemicals and modulate olfactory sensory neuron activity (Lemons et al., 2017; Lei et al., 2018; Nadjsombati et al., 2018; Schneider et al., 2018). The only commonality among these Skn-1a-dependent chemosensory cells, including taste cells, is their expression of Trpm5 (Yamashita et al., 2017). Therefore, sodium-taste cells are the first, very unique population of Skn-1a-dependent chemosensory cells that lack of Trpm5 expression. Other unidentified Skn1a-dependent chemosensory cells devoid of Trpm5 expression may exist. Genetic tools to mark Skn-1a ${ }^{+}$cells will help identify such novel chemosensory cells.

Taste bud cells have been classified into four types based on their ultra-microscopic morphologic features. This morphologic classification correlates with molecular features: Type I cells appear to be non-sensory supporting cells that lack voltage-gated $\mathrm{Na}^{+}$currents (Medler et al., 2003) and express Entpd2 that hydrolyzes extracellular ATP released from other taste bud cells as a neurotransmitter (Finger et al., 2005; Bartel et al., 2006; Vandenbeuch et al., 2013); Type II cells are taste cells expressing GPCRs and signaling molecules including $\operatorname{PLC} \beta 2, \mathrm{IP}_{3} \mathrm{R} 3$, and Trpm5; Type III cells are Pkd2/1 ${ }^{+}$cells; and Type IV cells are undifferentiated basal cells (Yang et al., 2000; Clapp et al., 2004; Chaudhari and Roper, 2010). Sodium-taste cells are sensory cells, but they are distinct from these cell types. Their molecular features, including the expression of Plcb2, Itpr3, Calhm1, Calhm3, and Skn-1a, requirement of Skn-1a for their generation, and apparent Calhm1/3 requirement for neurotransmitter release are reminiscent of Type II cells. They are however distinguished from Type II cells by their lack of Trpm5 and presence of $E N a C \alpha$ expression. Accordingly, sodium-taste cells can be regarded as a Type II cell subset, similar to the distinctions among Type II cells by their GPCR expression profiles. Ultramicroscopic morphologic studies in combination with immunohistochemistry in FuP taste buds where sodium-taste cells reside will be necessary to determine whether sodium-taste cells constitute a morphologically-distinct cell type in taste buds.

\section{References}

Bartel DL, Sullivan SL, Lavoie ÉG, Sévigny J, Finger TE (2006) Nucleoside triphosphate diphosphohydrolase-2 is the ectoATPase of type I cells in taste buds. J Comp Neurol 497:1-12.
Behrens M, Redel U, Blank K, Meyerhof W (2019) The human bitter taste receptor TAS2R7 facilitates the detection of bitter salts. Biochem Biophys Res Commun 512:877-881.

Beidler LM, Smallman RL (1965) Renewal of cells within taste buds. J Cell Biol 27:263-272.

Bigiani A, Cuoghi V (2007) Localization of amiloride-sensitive sodium current and voltage-gated calcium currents in rat fungiform taste cells. J Neurophysiol 98:2483-2487.

Chandrashekar J, Yarmolinsky D, Buchholtz L. v, Oka Y, Sly W, Ryba NJP, Zuker CS (2009) The taste of carbonation. Science 326:443445.

Chandrashekar J, Kuhn C, Oka Y, Yarmolinsky DA, Hummler E, Ryba NJP, Zuker CS (2010) The cells and peripheral representation of sodium taste in mice. Nature 464:297-301.

Chaudhari N, Roper SD (2010) The cell biology of taste. J Cell Biol 190:285-296.

Clapp TR, Yang R, Stoick CL, Kinnamon SC, Kinnamon JC (2004) Morphologic characterization of rat taste receptor cells that express components of the phospholipase $\mathrm{C}$ signaling pathway. J Comp Neurol 468:311-321.

Deckmann K, Filipski K, Krasteva-Christ G, Fronius M, Althaus M, Rafiq A, Papadakis T, Renno L, Jurastow I, Wessels L, Wolff M, Schütz B, Weihe E, Chubanov V, Gudermann T, Klein J, Bschleipfer T, Kummer W (2014) Bitter triggers acetylcholine release from polymodal urethral chemosensory cells and bladder reflexes. Proc Natl Acad Sci USA 111:8287-8292.

Dotson CD, Roper SD, Spector AC (2005) PLC $\beta 2$-independent behavioral avoidance of prototypical bitter-tasting ligands. Chem Senses 30:593-600.

Finger TE, Böttger B, Hansen A, Anderson KT, Alimohammadi H, Silver WL (2003) Solitary chemoreceptor cells in the nasal cavity serve as sentinels of respiration. Proc Natl Acad Sci USA 100:8981-8986.

Finger TE, Danilova V, Barrows J, Bartel DL, Vigers AJ, Stone L, Hellekant G, Kinnamon SC (2005) ATP signaling is crucial for communication from taste buds to gustatory nerves. Science 310:14951499.

Genovese F, Tizzano M (2018) Microvillous cells in the olfactory epithelium express elements of the solitary chemosensory cell trunsduction signaling cascade. PLoS One 13:e0202754.

Gerbe F, Sidot E, Smyth DJ, Ohmoto M, Matsumoto I, Dardalhon V, Cesses P, Garnier L, Pouzolles M, Brulin B, Bruschi M, Harcus Y, Zimmermann VS, Taylor N, Maizels RM, Jay P (2016) Intestinal epithelial tuft cells initiate type 2 mucosal immunity helminth parasites. Nature 529:226-230.

Glendinning Jl, Bloom LD, Onishi M, Zheng KH, Damak D, Margolskee RF, Spector AC (2005) Contribution of $\alpha$-gustducin to taste guided licking responses of mice. Chem Senses 30:299-316.

Harada S, Yamamoto T, Yamaguchi K, Kasahara Y (1997) Different characteristics of gustatory responses between the greater superficial petrosal and chorda tympani nerves in the rat. Chem Senses 22:133-140.

Hisatsune C, Yasumatsu K, Takahashi-Iwanaga H, Ogawa N, Kuroda Y, Yoshida R, Ninomiya Y, Mikoshiba K (2007) Abnormal taste perception in mice lacking the type 3 inositol 1,4,5-trisphosphate receptor. J Biol Chem 282:37225-37231.

Huang AL, Chen X, Hoon MA, Chandrashekar J, Guo W, Tränkner D, Ryba NJP, Zuker CS (2006) The cells and logic for mammalian sour taste detection. Nature 442:934-938.

Krasteva G, Canning BJ, Hartmann P, Veres TZ, Papadakis T, Mühlfeld C, Schliecker K, Tallini YN, Braun A, Hackstein H, Baal N, Weihe E, Schütz B, Kotlikoff M, Ibanez-Tallon I, Kummer W (2011) Cholinergic chemosensory cells in the trachea regulate breathing. Proc Natl Acad Sci USA 108:9478-9483.

Krasteva G, Hartmann P, Papadakis T, Bodenbenner M, Wessels L, Weihe E, Schütz B, Langheinrich AC, Chubanov V, Gudermann T, Ibanez-Tallon I, Kummer W (2012) Cholinergic chemosensory cells in the auditory tube. Histochem Cell Biol 137:483-497. 
Larson ED, Vandenbeuch A, Anderson CB, Kinnamon SC (2020) Function, innervation, and neurotransmitter signaling in mice lacking type-II taste cells. eNeuro 7:ENEURO.0339-19.2020.

Lei W, Ren W, Ohmoto M, Joseph F Urban J, Matsumoto I, Margolskee RF, Jiang P (2018) Activation of intestinal tuft cell-expressed Sucnr1 triggers type 2 immunity in the mouse small intestine. Proc Natl Acad Sci USA 115:5552-5557.

Lemons K, Fu Z, Aoude I, Ogura T, Sun J, Chang J, Mbonu K, Matsumoto I, Arakawa H, Lin W (2017) Lack of TRPM5-expressing microvillous cells in mouse main olfactory epithelium leads to impaired odor-evoked responses and olfactory-guided behavior in a challenged chemical environment. eNeuro 4:ENEURO.0135-17.2017.

Liu D, Liman E (2003) Intracellular $\mathrm{Ca}^{2+}$ and the phospholipid $\mathrm{PIP}_{2}$ regulate the taste transduction ion channel TRPM5. Proc Natl Acad Sci USA 100:15160-15165.

Ma Z, Taruno A, Ohmoto M, Jyotaki M, Lim JC, Miyazaki H, Niisato N, Marunaka Y, Lee RJ, Hoff H, Payne R, Demuro A, Parker I, Mitchell CH, Henao-Mejia J, Tanis JE, Matsumoto I, Tordoff MG, Foskett JK (2018) CALHM3 is essential for rapid ion channel-mediated purinergic neurotransmission of GPCR-mediated tastes. Neuron 98:547-561.

Matsumoto I, Ohmoto M, Narukawa M, Yoshihara Y, Abe K (2011) Skn-1a (Pou2f3) specifies taste receptor cell lineage. Nat Neurosci 14:685-687.

Matsumoto I, Ohmoto M, Abe K (2013) Functional diversification of taste cells in vertebrates. Semin Cell Dev Biol 24:210-214.

Medler KF, Margolskee RF, Kinnamon SC (2003) Electrophysiological characterization of voltage-gated currents in defined cell types of mice. J Neurosci 23:2608-2617.

Nadjsombati MS, McGinty JW, Lyons-Cohen MR, Jaffe JB, DiPeso L, Schneider C, Miller CN, Pollack JL, Nagana Gowda GA, Fontana MF, Erle DJ, Anderson MS, Locksley RM, Raftery D, von Moltke $J$ (2018) Detection of succinate by intestinal tuft cells triggers a type 2 innate immune circuit. Immunity 49:33-41.

Nomura K, Nakanishi M, Ishidate F, Iwata K, Taruno A (2020) Allelectrical $\mathrm{Ca}^{2+}$-independent signal transduction mediates attractive sodium taste in taste buds. Neuron 106:816-829.

Ohmoto M, Matsumoto I, Yasuoka A, Yoshihara Y, Abe K (2008) Genetic tracing of the gustatory and trigeminal neural pathways originating from T1R3-expressing taste receptor cells and solitary chemoreceptor cells. Mol Cell Neurosci 38:505-517.

Ohmoto M, Okada S, Nakamura S, Abe K, Matsumoto I (2011) Mutually exclusive expression of $\mathrm{G} \alpha$ ia and $\mathrm{G} \alpha 14$ reveals diversification of taste receptor cells in zebrafish. J Comp Neurol 519:1616-1629.

Ohmoto M, Yamaguchi T, Yamashita J, Bachmanov AA, Hirota J, Matsumoto I (2013) Pou2f3/Skn-1a is necessary for the generation or differentiation of solitary chemosensory cells in the anterior nasal cavity. Biosci Biotechnol Biochem 77:2154-2156.

Ohmoto M, Ren W, Nishiguchi Y, Hirota J, Jiang P, Matsumoto I (2017) Genetic lineage tracing in taste tissues using Sox2CreERT2 strain. Chem Senses 42:547-552.

Ohmoto M, Lei W, Yamashita J, Hirota J, Jiang P, Matsumoto I (2020) SOX2 regulates homeostasis of taste bud cells and lingual epithelial cells in posterior tongue. PLoS One 15:e0240848.

Oka Y, Butnaru M, Buchholtz L. v, Ryba NJP, Zuker CS (2013) High salt recruits aversive taste pathways. Nature 494:472-475.

Panneck AR, Rafiq A, Schütz B, Soultanova A, Deckmann K, Chubanov V, Gudermann T, Weihe E, Krasteva-Christ G, Grau V, Rey A. d, Kummer W (2014) Cholinergic epithelial cell with chemosensory traits in murine thymic medulla. Cell Tissue Res 358:737748.

Roebber JK, Roper SD, Chaudhari N (2019) The role of the anion in salt $(\mathrm{NaCl})$ detection by mouse taste buds. J Neurosci 39:62246232.
Sagai T, Amano T, Tamura M, Mizushina Y, Sumiyama K, Shiroishi T (2009) A cluster of three long-range enhancers directs regional Shh expression in the epithelial linings. Development 136:16651674.

Schneider C, O'Leary CE, von Moltke J, Liang H-E, Ang QY, Turnbaugh PJ, Radhakrishnan S, Pellizzon M, Ma A, Locksley RM (2018) A metabolite-triggered tuft cell-ILC2 circuit drives small intestinal remodeling. Cell 174:271-284.

Sollars SI, Hill DL (1998) Taste responses in the greater superficial petrosal nerve: substantial sodium salt and amiloride sensitivities demonstrated in two rat strains. Behav Neurosci 112:991-1000.

Stone LM, Finger TE, Tam PPL, Tan S-S (1995) Taste receptor cells arise from local epithelium, not neurogenic ectoderm. Proc Natl Acad Sci USA 92:1916-1920.

Taruno A, Vingtdeux V, Ohmoto M, Ma Z, Dvoryanchikov G, Li A, Adrien L, Zhao H, Leung S, Abernethy M, Koppel J, Davies P, Civan MM, Chaudhari N, Matsumoto I, Hellekant G, Tordoff MG, Marambaud P, Foskett JK (2013) CALHM1 ion channel mediates purinergic neurotransmission of sweet, bitter and umami tastes. Nature 495:223-226.

Tordoff MG, Ellis HT (2013) Taste dysfunction in BTBR mice due to a mutation of Itpr3, the inositol triphosphate receptor 3 gene. Physiol Genomics 45:834-855.

Tordoff MG, Ellis HT, Aleman TR, Downing A, Marambaud P, Foskett JK, Dana RM, McCaughey SA (2014) Salty taste deficits in CALHM1 knockout mice. Chem Senses 39:515-528.

Tu YH, Cooper AJ, Teng B, Chang RB, Artiga DJ, Turner HN, Mulhall EM, Ye W, Smith AD, Liman ER (2018) An evolutionarily conserved gene family encodes proton-selective ion channels. Science 359:1047-1050.

Vandenbeuch A, Clapp TR, Kinnamon SC (2008) Amiloride-sensitive channels in type I fungiform taste cells in mouse. BMC Neurosci 9:1.

Vandenbeuch A, Anderson CB, Parnes J, Enjyoji K, Robson SC, Finger TE, Kinnamon SC (2013) Role of the ectonucleotidase NTPDase2 in taste bud function. Proc Natl Acad Sci USA 110:14789-14794.

Wang Y, Zajac AL, Lei W, Christensen CM, Margolskee RF, Bouysset C, Golebiowski J, Zhao H, Fiorucci S, Jiang P (2019) Metal ions activate the human taste receptor TAS2R7. Chem Senses 44:339-347.

Yamaguchi T, Yamashita J, Ohmoto M, Aoudé I, Ogura T, Luo W, Bachmanov AA, Lin W, Matsumoto I, Hirota J (2014) Skn-1a/ Pou2f3 is required for the generation of Trpm5-expressing microvillous cells in the mouse main olfactory epithelium. BMC Neurosci 15:13.

Yamashita J, Ohmoto M, Yamaguchi T, Matsumoto I, Hirota J (2017) Skn-1a/Pou2f3 functions as a master regulator to generate Trpm5-expressing chemosensory cells in mice. PLoS One 12: e0189340.

Yang R, Crowley HH, Rock ME, Kinnamon JC (2000) Taste cells with synapses in rat circumvallate papillae display SNAP-25-like immunoreactivity. J Comp Neurol 424:205-215.

Yarmolinsky DA, Zuker CS, Ryba NJP (2009) Common sense about taste: from mammals to insects. Cell 139:234-244.

Yoshida R, Horio N, Murata Y, Yasumatsu K, Shigemura N, Ninomiya $Y(2009) \mathrm{NaCl}$ responsive taste cells in the mouse fungiform taste buds. Neuroscience 159:795-803.

Zhang Y, Hoon MA, Chandrashekar J, Mueller KL, Cook B, Wu D, Zuker CS, Ryba NJP (2003) Coding of sweet, bitter, and umami tastes: different receptor cells sharing similar signaling pathways. Cell 112:293-301. 